\title{
Correspondence
}

\section{Research in spirituality and mental health}

We are aware that the methodology, interpretation and evaluation of research on spirituality and mental health are complex matters which are not without their controversies and difficulties. The measurement of spirituality (which is to be contrasted with religiosity in this regard) is necessarily subjective, and easily prone to confounding with psychological variables. Alongside healthy forms of spirituality there are pathological forms of spirituality, and harmful forms of religion and religious practice, which are clearly detrimental to mental well-being. Not surprisingly, therefore, there are negative as well as positive associations in the research literature charting the relationships between spirituality, religiosity and mental health. For this reason we did not suggest in our article ${ }^{2}$ that 'research unequivocally shows an association between religiosity and well-being' ${ }^{3}$ but rather stated that 'research demonstrates largely positive associations between religiosity and well-being'. Our cited reference in support of this contention was the Handbook of Religion and Health, a volume written by Harold Koenig and his colleagues, which reviewed 1200 studies that were critiqued according to methodology and outcome. ${ }^{4}$ We might also have quoted Koenig's more recent review in the Canadian Journal of Psychiatry, ${ }^{5}$ which reaches a similar evidence-based conclusion that, although there are undoubtedly unhealthy forms of religious and spiritual involvement, the usual associations are with better coping and healthier functioning.

The editorial by Dan Blazer in the same issue of the Canadian Journal of Psychiatry, ${ }^{6}$ cited by Hansen \& Maguire, ${ }^{3}$ does not suggest that there is an unequivocal association between religiosity and well-being. Nor does it claim that 'The research findings are wildly contradictory and it would be unreasonable to draw any firm conclusion on the basis of current knowledge'. ${ }^{3}$ Rather, Blazer summarises Koenig's review as showing that 'studies to date generally support a positive association between (religion and (or) spirituality) and mental health'. However, Blazer does importantly acknowledge that this association is 'a tough topic to research'. One of the reasons he gives for this is that it is difficult to be objective on matters about which we hold very deep beliefs. Blazer goes on to warn that 'Neglect of the religious dimension, not to mention refusal to discuss religious matters with our patients, may seriously cut off meaningful communication and significantly undermine the therapeutic relationship'. He concludes that 'even though the task is tough, neglect is even more difficult to justify'.

Clinicians, researchers and patients do hold very deep beliefs on these matters. It is for this reason that it is important not to rely only on impressions derived from clinical experience but also to refer to evidence-based research and reviews. If we cannot eliminate bias in our interpretation of these findings, we can at least minimise it.

1 Crowley N, Jenkinson G. Pathological spirituality. In Spirituality and Psychiatry (eds CHC Cook, A Powell, A Sims): 254-72. RCPsych Publications, 2009.
2 Dein S, Cook CHC, Powell A, Eagger S. Religion, spirituality and mental health. Psychiatrist 2010; 34: 63-4.

3 Hansen LK, Maguire N. Divine intervention in mental health. Psychiatrist 2010; 34: 258-9.

4 Koenig HG. Handbook of Religion and Mental Health. Academic Press, 1998.

5 Koenig HG. Research on religion, spirituality, and mental health: a review. Can J Psychiatry 2009; 54: 283-91.

6 Blazer DG. Religion, spirituality, and mental health: what we know and why this is a tough topic to research. Can J Psychiatry 2009; 54: 281-2.

Christopher C. H. Cook, Chair, Spirituality and Psychiatry Special Interest Group, Royal College of Psychiatrists, Consultant Psychiatrist, Tees, Esk and Wear Valleys NHS Foundation Trust, Professorial Research Fellow, Department of Theology and Religion, Durham University, email: c.c.h.cook@durham.ac.uk; Simon Dein, Secretary, Spirituality and Psychiatry Special Interest Group, Royal College of Psychiatrists, Consultant Psychiatrist, Princess Alexandra Hospital, Senior Lecturer, University College London; Andrew Powell, Former Consultant Psychotherapist and Honorary Senior Lecturer, Oxfordshire Mental Healthcare Trust and University of Oxford; Sarah Eagger, Consultant Psychiatrist, Central and North West London NHS Foundation Trust, Honorary Clinical Senior Lecturer, Imperial College London, Co-Chair of the National Spirituality and Mental Health Forum.

doi: 10.1192/pb.34.7.304

\section{No religion or spirituality and mental health}

Many articles have been written about the importance of recognising patients' spiritual and religious beliefs and trying to understand them so that patients might be better engaged with services and that there might be a better therapeutic relationship. However, little has been written concerning agnostic or atheist views of patients. Surely this is of equal importance?

It is easy for those professionals who have religious beliefs to say a person's faith can be a source of coping - but how do they approach a person who has no beliefs? Do they try to convert them or claim to have enough faith for the two of them?

Can those professionals with strong beliefs or faith truly understand those with none? How do they align their own beliefs to ensure proper engagement and a satisfactory therapeutic relationship? The matter definitely needs further research and discussion.

Clive Mackin is a psychiatric nurse, email: pb@rcpsych.ac.uk doi: 10.1192/pb.34.7.304a

\section{Declare, declare!}

To me, the authors' response ${ }^{1}$ to Peter Bruggen's letter ${ }^{2}$ reflects a lack of understanding of the issue of bias in regard to declarations of interest. Surely, the most important reason for declarations of interest is to allow editors and readers to judge whether bias might have crept into a publication. Although the influence of the pharmaceutical industry, through financial relationships with clinicians or academics, is undoubtedly a source of bias, it is not the only source of bias that should be 